\title{
O papel do folclore na motivação para atividades físicas de idosas
}

CDD. 20.ed. 159

398.0981

796.018
Berta Leni Costa CARDOSO*

Luis Otávio Teles ASSUMPÇÃO*
*Universidade Católica

de Brasília.

\section{Resumo}

Existem muitos relatos sobre os benefícios biológicos da atividade física em idosos. Porém, o número de praticantes ainda não é satisfatório. Esse ponto controverso foi usado no presente artigo. Pesquisou-se sobre o uso do folclore local como um mecanismo educacional e motivacional útil no aumento da prática de atividades físicas para idosas. Foram entrevistadas idosas do Clube da Amizade em Caetité - BA, que foram motivadas e estimuladas pela dança. Este artigo também usou as reflexões de Paulo Freire, que admite o uso da cultura e contexto de vida pessoal como o mais importante meio de motivação e de educação. Os resultados provaram que é positivo o uso deste citado processo motivacional em estimular idosas nas suas aulas de educação física. Elas relataram que se sentem muito motivadas durante as aulas de dança enquanto podem escutar músicas que as fazem lembrar de seu passado, cultura e valores morais.

Unitermos: Motivação; Idosos; Folclore; Paulo Freire.

\section{Introdução}

Inúmeras pesquisas e trabalhos científicos na área bio-fisiológica demonstram os benefícios para a saúde da prática regular e sistemática de atividades físicas entre idosas: melhoria da capacidade cárdio-respiratória; do equilíbrio; do andar; do nível da manutenção e/ou aumento da densidade óssea; do controle da diabetes, da artrite e de doenças cardíacas; melhoria de ingestão de alimentos; diminuição da depressão; fortalecimento dos músculos das pernas e costas; melhoria dos reflexos; da sinergia motora; das reaçôes posturais; da flexibilidade; da manutenção do peso corporal; do aumento do fluxo sanguíneo para os músculos; diminuição das lesões musculares.

São vários os benefícios. No entanto, mesmo com estas comprovações, o que se constata é uma baixa adesão da população idosa a estas práticas.
Estamos, portanto, diante de uma questão de natureza cultural e social. Devemos pensar sobre hábitos e motivaçôes das idosas para a prática de atividades físicas.

Nesse trabalho estudamos uma possibilidade que nos pareceu desempenhar significativo papel motivador para a prática de atividades físicas regulares e sistemáticas entre idosas: as danças folclóricas e tivemos como objetivo a análise de danças folclóricas (Folia de Reis e Pastorinhas) como processo motivacional em aulas de Educação Física para idosas do Clube da Amizade da cidade de Caetité - BA; investigamos o papel dessas danças na motivação em aulas de Educação Física; investigamos os aspectos históricos, sociais e educacionais dessas danças folclóricas praticadas por essas idosas e tentamos compreender o papel, o lugar e a importância das danças regionais como instrumento de múltipla valia e aplicação.

\section{Metodologia}

A metodologia do trabalho é de natureza qualitativa, com utilização de entrevistas semi-estruturadas, em que foram resgatadas falas, experiências, vivências e significados das danças folclóricas para as idosas pesquisadas.
A pesquisa foi realizada com sete idosas do Clube da Amizade de Caetité (BA). A escolha recaiu sobre as frequentadoras mais antigas: a fundadora do clube, a presidente e cinco integrantes regulares. 
Durante três dias a cada semana, as idosas do Clube da Amizade se reuniam para aulas de educação física que mesclavam atividades diversas como: ginástica, danças, natação, hidroginástica, caminhada e alongamento, sempre sob supervisão de um professor de educação física. A cada época, as danças eram direcionadas por um tema. Por

\section{Resultados e discussão}

O número de idosas praticantes regulares de atividades físicas é relativamente baixo. Muito se pensa, se debate, se reflete sobre a motivação e a criação de hábitos de prática dessas atividades.

Nesse trabalho pensamos em que medida a valorização da cultura e das experiências de um grupo social por intermédio de suas danças e músicas folclóricas pode contribuir para os processos educacionais e motivacionais. Essas danças, no contexto do pensamento de Paulo Freire (1987), agiriam como "tema gerador".

Os conceitos analisados e desenvolvidos em nosso trabalho direcionam nosso olhar sobre o tema, possibilitando-nos apreender e dar sentido às falas das entrevistadas. Os significados implícitos serão revelados a partir desses referenciais conceituais estudados.

Estudamos diferentes interpretaçôes sobre a motivação para o processo educacional: intensidade do estímulo (relação entre a atividade e a motivação), padrão de estímulo (sequência de fases organizadas, com direção e persistência), despertar afetivo (antecipação de uma mudança afetiva), motivos sociais (requerem a presença ou a participação de outros indivíduos da mesma espécie) e motivos do "eu" (as quais contribuem para a defesa e o fortalecimento da imagem que cada ser humano possui de si). Vimos, ainda, as motivações internas (relacionadas a fatores profundos, instintos e necessidades) e as motivações externas (relacionadas a estimulações e a valores de ordem social).

Nosso trabalho se deteve, com maior profundidade, no que entendemos como "motivação externa". Para tanto, utilizamos as reflexōes do pedagogo Paulo Freire.

Esse autor afirma que, para se educar ou motivar um indivíduo para a prática de alguma atividade ou tarefa, deve-se, antes, considerar o contexto social e cultural no qual ele se insere. Costumes, valores, hábitos, histórias de cada um devem ser considerados e incorporados, uma vez que a ação do exemplo: nos meses de abril, maio e junho, as idosas tinham aulas e ensaiavam danças próprias da "Festa Junina”, nos meses de julho e agosto, elas ensaiavam danças e cantavam músicas folclóricas - cantigas, nos meses de outubro, novembro e dezembro, eram danças e músicas referentes à festa de Natal Pastorinhas e Reis.

professor, se quiser chegar ao homem real, deve ser a de comunicação, objetivando não o ser abstrato, mas o ser concreto inserido em uma realidade histórica.

Procuramos entender como essas reflexões teórico - conceituais sobre o processo motivacional se concretizam em nosso estudo sobre as idosas.

Entrevistamos as idosas, algumas no próprio clube, outras em suas casas. Foram entrevistas abertas, com roteiro e perguntas relativamente simples e esclarecedoras, sempre procurando deixá-las à vontade para falar, contar suas histórias, falar de suas experiências com a dança.

A partir das falas e vivências identificadas, categorizamos em cinco aspectos as diferentes interpretações das idosas sobre a dança: 1) recordação do passado; 2) alegria e auto-estima; 3) Pastorinhas e Reis; 4) Clube da Amizade; 5) Qualidade de vida.

\section{Recordação do passado}

Todas as entrevistadas destacaram e enfatizaram o desejo, o gosto e o prazer em dançarem. O que, basicamente, nos chamou a atenção foi a íntima relação que elas estabeleceram entre o ato de dançar e a recordação do passado. Não era qualquer dança que as fazia sentir vontade e motivação para realizar. Aquelas mais diretamente ligadas ao passado, que elas viveram, eram precisamente as que mais lhes interessavam.

Essas falas, atitudes e interesses das idosas, permitiu-nos melhor compreender o desejo, o gosto e o prazer a respeito da concepçáo de diferentes autores sobre a motivação, em especial de MIRANDA e Godel (2002), os quais enfatizaram o papel da música como motivação e prazer entre os indivíduos idosos no exercício de atividades aeróbicas.

Os estudos sobre a motivação humana sempre enfatizaram a importância da dimensão social para o despertar das ações. Segundo vimos, até mesmo 
os impulsos são influenciados pela cultura, como mostram os depoimentos abaixo:

"Então, lá a gente, além da merenda, tem música, dança, brinca, canta, revivendo o passado”.

A identificação do local como um espaço privilegiado, onde o passado não é visto como algo distante ou inoperante, é revelador: ele é base do próprio processo motivacional. Não é qualquer lugar capaz de motivar e despertar interesse. Alguns tem maior significado que outros. Compreender e interpretar o significado do espaço é essencial para melhor se entender a motivação.

A associação da dança ao passado, durante todo o tempo das observações, revelou-se estar presente na motivação das praticantes. Isto nos permitiu melhor entender os conceitos e reflexões de Paulo Freire, especialmente quando ele afirma:

[...] para esta concepção como prática da liberdade, a sua dialogicidade comece, não quando o educador - educando se encontra com os educando - educadores em uma situação pedagógica, mas antes, quando aquele se pergunta em torno do que vai dialogar com estes. Esta inquietação em torno do conteúdo do diálogo é a inquietação em torno do conteúdo programático da educação. [...] para o educador - educando, dialógico, problematizador, o conteúdo programático da educação não é uma doação ou uma imposição - um conjunto de informes a ser depositado nos educandos - , mas a devolução organizada, sistematizada e acrescentada ao povo daqueles elementos que este lhe entregou de forma desestruturada (Freire, 1987, p.83-4).

A presença do passado nas músicas é a expressão viva da relação dialógica proposta por Freire.

Não só as danças cumpriam esse papel motivacional. Também as músicas associadas às vivências volvidas despertavam grande interesse nas idosas pesquisadas. As idosas davam maior atenção, sentiam mais interesse em relação àquelas que cantavam em frente ao presépio. Diziam que aquele era o momento de reflexão, agradecimento e fé.

Cantou uma delas:

- Bailem, bailem, pastorinhas

Bailem com todo o primor,

Bailem que já é nascido

Nosso Deus e Salvador

- Glória nos céus e na terra

Hinos entoem subindo

Que os anjos adoram

Jesus em Belém nascido

- Resplandece o horizonte

Abre-se a corte celeste,
De graça tudo se veste

Rega a terra clara fonte,

Descem pastores do monte,

Em extremos admirados

Ao ver tanta formosura

Revestido em criatura

O nosso Deus sublimado

- Bailem, bailem, pastorinhas..

Embora enfatizem gostar de diferentes gêneros musicais em seu discurso, as idosas demonstraram apreciar mais as músicas que tenham algum significado em suas vidas:

A gente gosta das músicas mais antigas.

A gente tem preferência pelas músicas mais antigas.

O que a gente mais gosta é a Folia de Reis, pois a gente canta, dança, se alegra. Todo tipo de dança que a gente ensaia faz bem a gente, fazendo com alegria!

A presença das danças e músicas antigas, capazes de reviverem a tradição, leva-nos a refletir sobre seu papel nos processos educacionais e motivadores. Quando Freire (2002), Fernandes (2003), Nitsch (1980), Davidoff (2001), Brito (1994) e Tresca e De Rose Junior (2000) falaram sobre a importância da valorização da cultura, experiências, atitudes e valores em processos educacionais e motivacionais, foi-nos possível pensar nas idosas que dificilmente praticam educação física. Afinal, como despertá-las para atividades tão saudáveis como a educação física? Eis as questóes daqueles interessados na educação e na motivação. Certamente devemos - e este parece ser um campo a ser mais explorado pela Educação Física - dar maior atenção à contribuição da Pedagogia, da Psicologia, da Sociologia, da História, da Filosofia, da Antropologia no processo educacional. Ou ficamos mais atentos aos mecanismos pedagógicos e motivacionais estudados por essas disciplinas, ou realizamos estupendos trabalhos e estudos na área bio-fisiológicos, mas não conseguimos conscientizá-las de praticar tais atividades. $\mathrm{O}$ problema é, sobretudo, sócio-cultural-pedagógico!

Confirma essa ideia o fato de, ao serem questionadas sobre as músicas, danças e brincadeiras nas quais elas se sentiam mais motivadas para participarem, todas - sem exceção - responderam que, embora qualquer tipo de música toque no clube, elas sempre preferiram as mais antigas, ou seja, aquelas que elas conheciam desde criança; aquelas que elas viram e aprenderam com os pais, parentes e amigos, aquelas que as fizeram lembrar do passado, da infância, da juventude. "Essas músicas me fizeram levantar das cadeiras”, confessou-me uma delas. 
Só mesmo ficando bem atento para a profundidade e o alcance teórico das reflexóes de autores como Florestan Fernandes e Paulo Freire, compreendemos a importância da observação do ser em sua totalidade, aquele que pensa, age e constrói sua própria cultura.

Assim como as músicas e as danças, também as brincadeiras exerciam forte papel motivacional nas idosas.

Para elas, a brincadeira poderia ser qualquer uma: dança de mulher com mulher, dança da cadeira, retirada de outras pessoas para dançar, etc.

Fazemos muitas festinhas para a gente dançar.

Todo mês tem uma. Esse mês teve uma pizza

e aí teve canto, dança. A gente tem preferência

pelas músicas mais antigas, para gente recordar

o passado, né? Tem carnaval!

Também a oportunidade de se encontrarem demonstra um forte componente motivador. Ao nos dizerem que todo mês tem uma festa, as idosas valorizam a importância da periodicidade dos encontros e, assim, valorizavam a dimensão social de estarem sempre em contato.

No momento da dança, eu recordava o passado.

A apresentação depende da comemoração do

mês. Já a escolha de qual terno vamos apresentar

é coisa já de tradição. É bom recordar o passado.

Também a vestimenta é valorizada. De acordo com as idosas, o terno é escolhido segundo as experiências do grupo na infância e juventude, quando presenciavam ou participavam das danças de reis e pastorinhas. Há uma importância significativa na escolha dos ternos. Os ternos representam as vestimentas das pastoras que dançam. Essa escolha varia de acordo com fatos, atores, símbolos presentes na dança.

Terno, música, danças, brincadeiras representam para elas um "reviver" um universo social que, no mundo moderno, de certa forma, são relegadas ao esquecimento. Esse "reviver" é base de processos motivacionais.

Há muitos anos, a gente fazia o Reis. Tinha terno das rosas, terno das ciganas, terno das flores. Vai seguindo assim o passado. O passado me traz tanta felicidade.

$\mathrm{Na}$ Folia de Reis é esse momento, porque a gente louva com alegria, a gente fica cheia de amor, de alegria. A fé é muito importante para esse momento, pois sem fé não temos e não fazemos nada, nada tem sentido. Tudo isso a gente recorda o passado.

O momento da dança de Reis e Pastorinhas é maravilhoso. Sei lá, é um momento divino. Eu lembro da minha infância, que tinha o Reis lá.
Eis a idosa fazendo referência à sua infância, ao recordar os laços e sentimentos com sua família, principalmente seus pais. Esse momento, segundo ela, era de reflexão, de saudade, de recordação dos sentimentos. A dança de Reis permitia a recuperação desse passado.

As músicas e danças veiculadas nas aulas levavam algumas idosas a se emocionaram ao relembrar acontecimentos como a realização da festa de Reis na casa de seus pais. Lembravam de todo um ritual de preparo para a festa: as mães confeccionando as vestimentas da família (trajes próprios para a ocasiāo) e os agrados (comida e bebida) para os convidados; e os pais recepcionando os convidados.

Eu não fazia parte, mas o Reis que tocavam na minha casa, cantavam na porta... Então, tudo isso me faz lembrar.

A dança que eu mais gosto é o Reis. Gosto quando tem aula, tem apresentação. Todos os ternos eu tomei parte. Gosto do reis porque é assim, a gente faz em muitos lugares, apresenta. Nesse tempo, lembro do tempo que eu trabalhava, ensinava. Quando eu estou dançado o Reis, eu sinto uma alegria diferente, uma satisfação. Acho que essa alegria diferente tem a ver com minhas lembranças. Durante as apresentações e as aulas, a gente lembra assim, quer dizer, as nossas festas, a gente ia ao clube, no meu tempo, dançava, curtia assim bastante o São João, né?

Era uma festa bem badalada, bem alegre (risos). Tem relação com minhas lembranças de infância, de mocidade, está entendendo? Quando criança, a gente brincava São João, pulava fogueira, fazia comadre.

\section{Alegria e autoestima}

O desejo de danças e músicas que recuperavam o passado e, assim, despertavam maior interesse nas idosas integrantes do Clube da Amizade parece favorecer a melhoria da autoestima, o que faz parte de processos motivadores.

Um motivo muito apontado pelas entrevistadas para a prática das atividades físicas foi o fato de a dança proporcionar alegria a elas, como evidenciam os depoimentos abaixo:

Já apresentamos no Instituto (uma escola para crianças) umas duas vezes o Reis. Esse ano vai ter Reis de caixa. Vários grupos se apresentando numa competição. É um dia inteiro. É um dia de alegria.

Nós ficávamos já esperando o Reis lá da roça. 
Tinha bolo, tinha tudo. Quando a gente via, já na porta cantando, era uma alegria.

O que a gente mais gosta é a Folia de Reis, pois a gente canta, dança, se alegra.

Todo tipo de dança que a gente ensaia faz bem à gente, fazendo com alegria, né?

$\mathrm{Na}$ Folia de Reis é esse momento, porque a gente fica cheia de amor, de alegria.

Quando eu estou dançando o Reis, eu sinto uma alegria diferente.

Acho que essa alegria tem a ver com minhas lembranças.

A alegria e entusiasmo presentes nas danças permitia às idosas lembrarem-se dos momentos que viveram com seus pais, irmãos, familiares. Recordavam-se dos laços de afeto que os uniam, das festas, dos abraços, da segurança que isso trazia.

Essa reflexão remete-nos aos estudos que consideram a animação e a recreação elementos especiais do processo motivacional. Em sentido semelhante discorre a teoria de Freire, ao tratar da educação problematizadora, quando os educandos são concebidos como investigadores, os quais se relacionam por meio do diálogo; aos estudos de Fernandes (2003), ao conceber o folclore como realidade social; aos estudos que propõem a exploração das manifestações da Cultura Corporal no programa de Educação Física; e com aqueles que propõem a dança como tema gerador.

A associação da dança com a alegria sempre esteve presente, o que pode ser reforçado por alguns depoimentos já citados anteriormente.

O conjunto das entrevistas expõe a relação entre a juventude e a terceira idade: segundo elas, os jovens não demonstram coragem nem interesse em dançar o Reis e as Pastorinhas; são tímidos; possuem menor domínio sobre as danças folclóricas.

As danças folclóricas, de certa forma, resgatam a autoestima, pois as idosas exercem maior domínio sobre elas.

Não é de qualquer festa que elas falam, quando se referem à alegria e à melhora de autoestima. $\mathrm{O}$ fato de elas terem criado as próprias festas é um elemento importante. Enquanto as festas das idosas são abertas à participação dos jovens, as destes são fechadas. No Clube da Amizade, qualquer pessoa é bem vinda, seja idoso, jovem ou criança, havendo espaço e brincadeiras para todo tipo de idade. Relatam que as festas dos jovens não são abertas, dificilmente são convidadas e, quando o são, sentem-se deslocadas e sem lugar, não havendo muita interação. Dizem elas:

Festas das idosas:

Todo mundo dança muito, viu! E também não só a gente da terceira idade.
E dançam, brincam do mesmo jeito que a gente, da mesma maneira.

$\mathrm{Na}$ micareta da terceira idade, a gente entra.

Em setembro, é a festa do Ancião.

Engraçado, nas nossas festinhas, os jovens também dançam, mas tem hora que os velhos dominam mais que os novos.

Sair aí assim, cantando Reis, você está doida. O jovem de hoje não tem essa coragem de sair assim, não.

Depois que a gente começou a dançar o Reis pelas ruas, que o jovem se animou.

Sobre as festas dos jovens:

$\mathrm{O}$ jovem é muito tímido. Eles não têm coragem de chegar e dançar assim.

Você não se sente bem em ir para uma festa aí qualquer e misturar com o jovem para dançar, para brincar.

Hoje você não pode mais ir às festas, porque não tem lugar para a gente, né?

Para as idosas, a dança no Clube faz bem, porque é o espaço em que elas se sentem seguras e motivadas a participarem, onde todos são bem vindos.

A existência desse espaço próprio de ação remetenos a refletir acerca da teoria de Freire, quando diz que, para motivar e educar, deve-se produzir um meio favorável para tal, seja o meio como espaço físico, seja quanto aos aspectos sociais, emocionais e culturais.

E foi muito vivido o Reis. Hoje é muito admirado até pela mocidade.

Tudo sem vergonha também, porque o jovem não tem coragem de fazer isso. Tinha vergonha com tudo. Sair aí assim, cantando reis, você está doida. O jovem de hoje não tem coragem de sair assim não. Eles não têm muita coragem para fazer isso, não, mas admiram a gente. E sempre perguntam: esse ano não vai ter não? Cobram da gente.

Pelo menos aqui é uma maneira da gente se encontrar e, assim, conciliar bate - papo, umas criam, uma conta um caso, outra conta outro e, assim, a gente vai levando a vida mais alegre um pouco, né?

As idosas são concebidas como precursoras das apresentações de Reis e Pastorinhas em Caetité - BA, conforme os depoimentos abaixo:

Apesar de idosos, todos os assinantes do documento têm a consciência do dever cumprido e uma bagagem muito grande na vida, podendo servir de modelo de vida para os jovens de hoje. Apesar de sexagenária, minha coragem, minha força, meu entusiasmo (...)

Depois que a gente começou a dançar o Reis pelas ruas, que o jovem se animou. Eles não têm 
muita coragem para fazer isso não, mas admiram a gente. E sempre perguntam: - Esse ano não vai ter não? Cobram da gente.

Esses depoimentos revelam a atualidade de pensamentos de Freire para a qual, como vimos, o ato de educar e motivar está intimamente associado à cultura e às experiências do educando.

Chamou-nos a atenção a utilização, pelas idosas, em seus depoimentos, dos vocábulos referentes à alegria (15 vezes), "coragem" (cinco vezes) e "animou" (uma vez), nas aulas de dança.

Ao conceber a dança como um fato folclórico, FERNANDES (2003) contribui ao postular o valor educativo do folclore, por meio do jogo e da recreação. BRANDÃo (1986) corrobora, ao destacar que o fato folclórico reproduz-se, em função de o mesmo ser vivo, dinâmico e significativo para a vida e para a circulação de trocas simbólicas, de bens, de serviços e de ritos entre as pessoas que constituem os grupos sociais.

O uso desses vocábulos corrobora o estudo de Tresca e De Rose Junior (2000) que, ao compararem a motivação intrínseca entre alunas de $5^{\mathrm{a}}$ e $6^{\mathrm{a}}$ séries praticantes e não praticantes de dança, nas aulas de Educação Física, evidenciaram a presença das palavras "feliz", "ânimo" e "coragem" nas respostas das integrantes do grupo praticante da dança. Relaciona-se, ainda, com o estudo de Moreira (2000), quando essa autora relaciona o termo "qualidade de vida" e "bem-estar" (felicidade) com elementos objetivos (bens materiais, serviços, necessários à manutenção da dignidade humana).

\section{Pastorinhas e Reis}

As Pastorinhas são uma dança folclórica de caráter religioso. Esse estudo partiu da associação da cultura e religiosidade de sua origem, pois é uma dança católica fortemente vinculada aos valores e crenças de um povo. Nessa dança, percebe-se a presença de fortes grupos de pastores e pastoras que dançam, segundo a tradição.

Os grupos de pastorinhas são uma reminiscência da tradição e dos fatos evangélicos que falam dos pastores que, convocados por um anjo, foram até uma manjedoura, assinalada por uma estrela, onde encontraram um menino recém-nascido com seus pais.

As danças folclóricas, especialmente as Pastorinhas e os Reis, na visão das integrantes do Clube da Amizade, representam o seu universo. O folclore, portanto, desempenha significativo papel motivador na educação. Os depoimentos das idosas registraram a importância das danças folclóricas
(Reis e Pastorinhas) em seus desejos e interesses em praticarem atividades físicas, no caso, as danças. E foi muito vivido o reis. Hoje é muito admirado até pela mocidade.

As casa nos convidam, a gente dança, a gente brinca. Já apresentamos no Instituto (uma escola para crianças) umas duas vezes o Reis.

O padre é um senhor que já tem 90 anos e adora participar. Ele vai para as excursões com a gente. No dia de Reis, ele vai acompanhando.

A primeira apresentação foi com o bispo, e o padre acompanha, o monsenhor.

Nessas danças folclóricas, que bem representam o universo dessas idosas, elas se sentem à vontade, felizes, mais motivadas para participarem.

Através delas, as idosas se sentem mais seguras perante a sociedade, sentindo-se parte dela.

Por meio dessas danças, esses atores sociais se sentem parte do processo de aprendizagem. Os seus conhecimentos adquiridos em sua prática de vida são tão importantes quanto os trazidos pelo professor de Educação Física. Estabelece-se, portanto, uma educação dialógica.

Essa autoafirmação perante o grupo é de extrema relevância para os processos motivacionais. Segundo algumas teorias motivacionais, a pessoa se adapta aos processos de aprendizagem, em virtude da existência de um forte estímulo - ou motivo - que pode ser inferido da aprendizagem. Para essas idosas, as danças e as músicas realizadas durante as aulas traziam mais sentido à prática, favorecendo todo o processo de educação e motivacional.

Para Freire (1996), ensinar não é a mera transferência de conhecimentos, mas conscientização e testemunho de vida. Para ele, torna-se imprescindível a solidariedade social e política para se evitar um ensino elitista e autoritário. Ao proporcionar às idosas aulas com danças e músicas que as fizessem relembrar o passado, o processo educacional ganhava maior motivação.

\section{Clube da amizade}

Outro assunto de grande relevância para a construção do processo motivacional, aparecendo em todas as entrevistas, foi o Clube da Amizade. Os motivos que levam as idosas a participarem dessa instituição foram registrados: necessidade de encontros, amizade, combate à solidão, dança e melhoramento da saúde.

O clube da Amizade realiza atividades de filantropia em Caetité para pessoas das mais diversas faixas etárias, conforme demonstram os depoimentos: 
O Clube também realiza toda semana uma sopa para pessoas carentes. No Natal, distribui roupas, enxoval para recém-nascido. Durante o ano, tem o grupo de costura, que faz as roupas e os cobertores. Temos uma sala com máquinas de costura para criança e, no fim do ano ou quando há necessidade, nós distribuímos as roupas.

$\mathrm{Na}$ Festa do Anciāo, convidamos aqueles que não têm oportunidade. Fazemos cobertas, roupas nas máquinas doadas e doamos tudo.

Objetivos culturais e filantrópicos são também perseguidos pelo corpo social do Clube.

Vale destacar que, na visão das idosas, o Clube da Amizade lhes possibilita participar da preservação cultural, de turismo, de excursões, como evidenciam os depoimentos:

A gente já visitou vários pontos turísticos, cidades históricas, São Paulo, Gramado, Canelas, Aparecida do Norte.

Ele [o padre] vai para as excursões com a gente. Fizemos uma excursão lá em Correntina. Foi uma maravilha. Fizemos em Livramento, em Porto Seguro, Aparecida do Norte.

Fizemos o lançamento do jornal "A melhor idade".

Registrou-se que a maioria das opiniōes considera a "necessidade de encontros" o principal motivo para a participação no Clube da Amizade.

Os estudos de Braghirolli, Bisi, Rizzon e NicoletTO (2003) e BRITo (1991, 1994) dão luz a esse estudo quanto às concepçóes de motivos sociais; de motivações externas relacionadas a estimulações e a valores de ordem social, relacional; de afirmação social; do fator animação - recreação. A possibilidade de estarem entre seus pares motivava as idosas a participarem do clube e de suas atividades físicas. Esse encontro era munido de sentimentos e lembranças que motivavam para a prática. (...) pensamos em montar um grupo que pudesse provocar encontros, se alegrar, porque a terceira idade está assim cortada, né? Hoje você não pode mais ir às festas, porque não tem lugar para a gente, né? Todo mês a gente promove qualquer coisa para a gente se encontrar.

O clube surgiu da necessidade da gente se encontrar. Aqui [referência à cidade] não tem nada para nossa idade, para a terceira idade.

Lá é para a gente estar se encontrando, celebrando, se alegrando. Nós mesmos, os idosos, sentimos a necessidade de criar o Clube.

Tudo serve para a gente se encontrar, se alegrar. Porque a terceira idade está assim esquecida. Pelo menos aqui é uma maneira da gente se encontrar.
Essa necessidade de encontros é reforçada em razão de as idosas integrantes do Clube da Amizade, muitas vezes, sentirem-se marginalizadas, excluídas, esquecidas, sem lugar e sem tempo. Depois de aposentadas, elas relataram que na cidade reduzem-se as atividades para elas: sentem-se sozinhas, algumas já são viúvas, os filhos saíram para estudar, ficaram com menos possibilidades de conversas, de expressão de sentimentos, etc. Os depoimentos de algumas são bastante esclarecedores:.

Aqui não tem lugar para nossa idade, para a terceira idade.

Porque a terceira idade está assim esquecida.

Então, com saudade do tempo da gente (...).

Aqui não tem nada para nossa idade, para a

terceira idade.

(...) porque aqui gente velho não tem acesso em nada.

As falas das idosas ganham sentido quando as interpretamos sob a perspectiva de TuBINO (1992), quando ele analisa o esporte - educação. Segundo ele, essa atividade privilegia os aspectos da integração social, da atividade física educativa e do desenvolvimento psicomotor.

As ideias de TODARO (2002) também contribuíram para esse entendimento ao conceber a dança como momento de convívio social, permitindo melhorar e aumentar o círculo de relacionamentos entre os participantes do grupo. Essa possibilidade de encontros motivava as idosas do Clube da Amizade a participarem das aulas de dança.

Cabe registrar, ainda, que as idosas fazem referência à sede do Clube da Amizade e às atividades físicas ali desenvolvidas, consideradas por elas como próprias para a terceira idade, como evidenciam os depoimentos abaixo:

A sede tem um campo de basquete, piscina, tem professor de ginástica, natação três vezes por semana. Quando está frio, é mais ginástica. Tem um professor que é jovem. Ele é formado em Educação Física. Ele gosta de dar alongamento antes da aula.

Com a fundação do Clube da Amizade, em 1992, não só pela necessidade prática pelo exercício físico dos associados, como pelo interesse de incentivar e desenvolver práticas esportivas na comunidade pelo presidente (...)

Temos professor de ginástica. As atividades são próprias para a terceira idade. Ginástica, natação, eventos ... Não colocamos só atividades de lazer. Ginástica, natação, caminhada, festas, apresentaçôes acontecem no Clube. 
A gente vai para lá tomar banho de piscina, fazer exercícios (...)

Gosto de participar de todas as aulas, de todas as atividades. Me sinto bem melhor. Ainda mais porque eu fui professora de Educação Física. Era uma pessoa muito ativa. Trabalhei 28 anos com criança. Eu adorava. Toda vida eu gostei muito de esporte.

O fato de terem um lugar específico, com atividades especiais direcionadas às suas necessidades, tornava a prática de danças em aulas de Educação Física mais interessante e atraente, contribuindo, então, para o processo educacional e motivacional das idosas.

\section{Qualidade de vida}

MoreIRA (2000) relaciona qualidade de vida ao bemestar (felicidade) e a elementos objetivos (bens materiais, serviços, necessários à manutenção da dignidade humana). Os estudos de Leite, Cappellari e Sonego (2002) contribuem para nossa reflexão, quando investigam a relação entre grupos de convivência e a terceira idade. Segundo essas autoras, houve mudanças na vida das idosas após o ingresso nos grupos de convivência, como melhoria das relações domiciliares, melhora na habilidade motora, melhora da saúde mental, aumento do círculo de amizades e maior número de viagens, acompanhando os grupos, resgate da vaidade, prazer, satisfação, alegria, entre outros.

As ideias sobre qualidade de vida destacam a melhoria e favorecimento do bem-estar físico, psíquico, emocional e social. Essas reflexôes dão luz a nosso estudo, justificando-se nas declarações das idosas de que as aulas de dança conseguem proporcionar esse bemestar. Todas as idosas consideram que a participação no Clube da Amizade melhorou a qualidade de vida.

Depois de começar a participar do Clube, acho que minha vida mudou completamente. Mudou tudo (risos). Eu, por mim, acho que vou viver

\section{Conclusão}

As danças folclóricas Pastorinhas e Reis motivam as integrantes do Clube da Amizade, localizado em Caetité - BA, a praticar, com prazer, atividades físicas. Elas constituem uma prática educativa, em que se respeitam e se valorizam os saberes dessas educandas. Estabelece-se, por meio delas, uma educação dialógica, a qual favorece a melhoria da autoestima desses atores sociais, que se sentem marginalizados pela sociedade em função de sua idade cronológica. cem anos, com essa vida que levo aqui (risos). Ah, vou viver uns 100 anos! Fui operada, tirei o seio, não sinto falta de nada. Não tive problema, não quis colocar prótese. Para quê? O grupo foi uma maravilha na minha vida. Isso aqui é o meu mundo. Uma maravilha!

O que mudou na minha vida depois de participar no Clube foi porque a gente deixa de ficar assim só em casa, só triste, o convívio, o bate-papo. Você se torna assim mais comunicativa, mais alegre, né? E esquece as tristezas, vai deixando um pouquinho as tristezas de lado, né? Eu que já perdi meu marido, a gente fica saudoso, né? Pelo menos aqui, é uma maneira da gente se encontrar, e assim conciliar, bate-papo, umas criam, uma conta um caso, outra conta outro e, assim, a gente vai levando a vida mais alegre um pouco, né? Esquecendo os problemas.

O conjunto de entrevistas evidencia que as aulas de danças folclóricas (Pastorinhas e Reis), as quais motivam a prática de atividades físicas por parte das idosas, contribuíram para a melhoria do bem-estar físico, psíquico, emocional e social das integrantes do Clube da Amizade.

Quando tem qualquer coisa para acontecer, a gente reúne. Tem o coralzinho, reúne, ensaia na própria aula. Tudo é bom, né? Tudo é agradável. Saímos para comer pizza. Realizamos café da manhã. Por causa da idade, a gente vai morrer? Não, pelo contrário. Enquanto tiver vida, nós estamos vivendo, procurando nos alegrar, viver bem, certo? Enquanto tiver saúde e poder..., né? A gente, enquanto puder viver, enquanto puder ter disposição, deve brincar, distrair e ter um pouco de alegria. Não importa a idade.

Depois que entrei no Clube, acho que minha vida melhorou o convívio com as colegas, com os outros. A própria ideia. Para mim, foi bom por isso.

Esse processo educacional prioriza os conhecimentos adquiridos por essas idosas e aproxima a educação à cultura dessas educandas, à sua realidade concreta, ao seu contexto social e cultural, promovendo realmente uma comunicação entre seres humanos. Concebe-se, assim, a educação como um ato cognoscente, privilegiando a identidade cultural das educandas.

Essas danças se constituem, ainda, naquilo que FERnANDEs (2003) concebe como ocorrências 
folclóricas, exprimindo modalidades do comportamento coletivo e vinculando-se às condições de vida social organizada de uma comunidade.

Essas práticas educativa se aproximam daquilo que Tubino (1992) concebe como esporte - educação, que prioriza aspectos como integração social, atividade física educativa e desenvolvimento psicomotor; das motivaçôes externas, propostas por BRITO (1994), as quais se relacionam a estimulações e a valores de ordem social, relacional, como estatuto, afirmação, hierarquia e diferença; das motivações de grupo social (motivos sociais) e culturais, concebidas por NiTsCH (1980).

Essa investigação evidencia, ainda a importância do Clube da Amizade para essas idosas, a sua organização e a sua atuação nas várias esferas da sociedade, num mundo marcado pelo viés econômico, pelo lucro, pelo egoísmo, pela exclusão social e pela escassez de políticas públicas para esse segmento tão importante para a sociedade

\begin{abstract}
The role of folklore in the motivation for physical activity of elderly

There are many reports about the biological benefits of the physical activity in older individuals. However the number of physically active elderly is still not satisfactory. This controversial point was used in the present article. It searches if the use of the local folklore as an educating and motivating mechanism was useful for increasing physical activity practices in older individuals. Individuals from "Clube da Amizade" in Caetite city, Bahia (Brazil) were interviewed to assess how folkloric dance was used to motivate them in physical education classes. This article also uses the Paulo Freire reflections that admit the use of regional cultural aspects and the life context as the most import strategy to teach and motivate the participants. The results indicated that is positive to use this referred motivational process to stimulate old ladies in the physical education classes. The interviewed ladies reported that they feel very stimulate during dance classes while they listen to music that makes them to remember past times, culture and moral values.
\end{abstract}

UnITERMS: Motivating; Old age; Folklore; Paulo Freire.

\title{
Referências
}

BRAGHIROLLI, E.M.; BISI, G.P.; RIZZON, L.A.; NICOLETTO, U. Piscologia geral. 23.ed. Petrópolis: Vozes, 2003. BRITO, A.P. Psicologia, idosos e exercício. Lisboa: Faculdade de Motricidade Humana/Universidade Técnica de Lisboa, 1991. . Psicologia do desporto. Lisboa: Omniserviços, 1994.

BRANDÃO, C.R. O que é folclore. 7. ed. São Paulo: Brasiliense, 1986.

DAVIDOFF, L.L. Introdução à psicologia. Tradução de Lenke Perez. 3 ed. São Paulo: Makron Books, 2001.

FERNANDES, F. O Folclore em questão. 2 ed. São Paulo: Martins Fontes, 2003.

FREIRE, P. Pedagogia do oprimido. 17 ed. Rio de Janeiro: Paz e Terra, 1987.

Pedagogia da autonomia: saberes necessários à prática educativa. 6 ed. Rio de Janeiro: Paz e Terra, 1996.

Pedagogia da esperança: um reencontro com a pedagogia do oprimido. 9 ed. Rio de Janeiro: Paz e Terra, 2002.

LEITE, M.T.; CAPPELLARI, V.T.; SONEGO, J. Mudou, mudou tudo na minha vida: experiências de idosos em grupos de convivência no município de Ijuí/RS. Revista Eletrônica de Enfermagem (on-line), v.4, n.1, p.18-25, 2002. Disponível em: <http:/www.fen.ufg.br/revista/revista4_1/Pdf/Mudou.pdf>.

MIRANDA, M.L.J.; GODELI, M.R.C.S. Avaliação de idosos sobre o papel e a influência da música na atividade física.

Revista Paulista de Educação Física, São Paulo, v.16, n.1, p.86-99, 2002.

MOREIRA, M.M.S. Trabalho, qualidade de vida e envelhecimento. 2000. Dissertação (Mestrado) - Fundação Oswaldo Cruz, Escola Nacional de Saúde Pública, Rio de Janeiro, 2000. Disponível em: <http://portalteses.cit.fiocruz.br/trans. php?scret=thes $>$. Acesso em: 8 dez. 2005. 
NITSCH, J. Técnicas de motivação no esporte. Revista Brasileira de Educação Física e Desportos, Brasília, n.46. p.35- 46, 1980.

TODARO, M.A. Dança e envelhecimento: conceitos, pesquisas e experiências. A Terceira Idade, São Paulo, v.13, n.24, p.28-37, 2002.

TRESCA, R.P.; De ROSE JUNIOR, D. Estudo comparativo da motivação intrínseca em escolares praticantes e não praticantes de dança. Revista Brasileira de Ciência e Movimento, Brasília, v.8 n.1 p.9-13, 2000.

TUBINO, M.J.G. Dimensões sociais do esporte. São Paulo: Cortez, 1992.

ENDEREÇO

Berta Leni Costa Cardoso R. Rui Barbosa, 260 - Anexo A 46430-000 - Guanambi - BA - BRASIL e-mail: bertacosta@bol.com.br
Recebido para publicação: 03/ 04/2009

1a. Revisão: 23/03/2010

2a. Revisão: 24/09/2010

Aceito: 01/ 10/2010

64 • Rev. bras. Educ. Fís. Esporte, São Paulo, v.25, n.1, p.55-64, jan./mar. 2011 